\title{
Chronic Lung Pathologies That Require Repair and Regeneration
}

\author{
Roderick de Hilster, Minghui Li, Wim Timens, \\ Machteld Hylkema, and Janette K. Burgess
}

\section{Abbreviations}

AEC Alveolar epithelial cell

BPD Bronchopulmonary dysplasia

CF Cystic fibrosis

CFTR Cystic fibrosis transmembrane conductance regulator

CL- Chloride

COPD Chronic obstructive pulmonary disease

DAD Diffuse alveolar damage

ECM Extracellular matrix

FDA Federal drug agency

HCO3- Bicarbonate

ILD Interstitial lung disease

IPF Idiopathic pulmonary fibrosis

MSC Mesenchymal stem cell

PAH Pulmonary arterial hypertension

TGF- $\beta$ Transforming growth factor- $\beta$

R. de Hilster $\cdot$ M. Li $\cdot$ W. Timens $\cdot$ M. Hylkema

J. K. Burgess $(\bowtie)$

The University of Groningen, University Medical

Center Groningen, Department of Pathology

and Medical Biology,

Groningen, The Netherlands

University Medical Center Groningen, University of Groningen, GRIAC (Groningen Research Institute for Asthma and COPD), Groningen, The Netherlands e-mail: r.h.j.de.hilster@umcg.nl; m.li@umcg.nl; w.timens@umcg.nl; m.n.hylkema@umcg.nl; j.k.burgess@umcg.nl
TNF- $\alpha \quad$ Tumour necrosis factor- $\alpha$

UIP Usual interstitial pneumonia

WHO World Health Organisation

\subsection{Introduction}

Lung diseases are, when cumulatively added, the main cause of mortality worldwide $[1,2]$, and the full impact of these diseases is yet to be realised. The incidence and accuracy of diagnosis of chronic lung diseases, such as chronic obstructive pulmonary disease (COPD) and pulmonary fibrosis, continue to increase worldwide. Lung diseases affect both the individual and the surrounding society extensively, with impact of these diseases on the family, work place and health economics, including increasing costs for health care while a majority continues to be incurable. For most chronic lung diseases little progress has been made, in recent years, in the development of therapeutic strategies for managing these burdensome pathologies. There is an urgent need to increase our understanding of the mechanisms underlying these diseases and for innovative approaches that will lead to the clinical breakthroughs that are currently lacking.

The lung is built of airways and lung parenchyma and blood vessels. Specialised cells that reside within, and in relation with, defined regions of the extracellular matrix (ECM) make 
up the main building blocks of these components. As one of the few organs that are directly exposed to environmental insults, the lung has an effective endogenous repair system that enables homeostasis to be maintained within the tissue. Whilst the exact mechanisms underlying most chronic lung diseases are not well understood, in many instances it is recognised that an aberration of the inherent repair process probably contributes to the pathophysiology that results in the diseased outcome [3-9]. The lung has a slow yet constant cell turnover that nevertheless cannot always cope with the loss of tissue and cells during (severe) injury or chronic disease [5]. During ageing, the respiratory system undergoes structural remodelling affecting both elements of the ECM and the cells, which leads to loss of elasticity and enlargement of alveolar spaces, with eventual airway narrowing because of loss of elastic recoil [10]. The result is a lung more susceptible to both acute and chronic insults, which becomes dysfunctional and with a lower breathing capacity that debilitates the patient [11].

Endogenous progenitor cells (stem cells) have been recognised in many organs, including the lungs [12-15]. Understanding the role of stem cells in maintaining a population of cells that are able to facilitate the endogenous repair processes that maintain tissue homeostasis is currently an area of intense research interest. Emerging knowledge of how these repair processes are disrupted in chronic lung diseases and the potential to capitalise upon the regenerative capacity of these cell populations as the much-anticipated advance for clinical management for these devastating diseases is raising the hopes of the field worldwide.

\subsection{Chronic Lung Disease Pathologies That May Benefit from Regeneration Approaches}

\subsubsection{Chronic Obstructive Pulmonary Disease (COPD)}

Chronic obstructive pulmonary disease (COPD) is characterized by progressive airflow limita- tion that is not fully reversible and results mainly from the interplay between genetic susceptibility and environmental stimuli [16]. COPD is currently the third leading cause of death in the world [17], attributed to exposure to smoke by cigarette smoking and/or indoor cooking or by other harmful particles [19]. Alpha l-anti-trypsin deficiency is a genetic cause responsible for a minority of COPD incidence [18, 19]. The incidence of COPD is more often seen at a higher age, in particular because of the slow development of the disease before the clinical deterioration becomes apparent; the disease diagnosis therefore increases with age, peaking for patients between age 65 and 74, although patients who develop disease at a younger age usually have more severe disease. More than three million people died of COPD in 2012 accounting for $6 \%$ of all deaths worldwide. Globally, the COPD burden is projected to increase in coming decades because of continued exposure to COPD risk factors, as mentioned above, and ageing of the population seriously impacting the health costs associated with managing these patients.

\subsubsection{Pathology of COPD}

The pathological changes in COPD are observed in the central airways, small airways, alveolar space and vasculature [20-22] (see Fig. 1.1). The central airway alterations include goblet cell hyperplasia, which are associated with the enlargement of mucus-producing glands and squamous cell metaplasia [23]. These changes are related to enhanced mucus production and cough in chronic bronchitis. The small airways, usually defined as airways with less than $2 \mathrm{~mm}$ internal diameter without cartilage, are considered the major site of increased airflow resistance in most patients with COPD [24]. Small airway wall thickening is observed, with increased smooth muscle mass and infiltration of inflammatory cells, and some alterations of epithelial cell differentiation leading to a variable shift of club- and ciliated cells to more goblet cells. This small airway wall thickening together with the loss of peri-bronchial elastic recoil is considered as the predominant cause of airflow limitation [10, 21]. Infiltration of 
Fig. 1.1 Representative photomicrographs of human lung tissue sections stained with hematoxylin and eosin illustrating disease pathological features from a 10-week-old infant who died from bronchopulmonary dysplasia, and adults with chronic obstructive pulmonary disease, idiopathic pulmonary fibrosis, pulmonary arterial hypertension, cystic fibrosis and acute respiratory distress syndrome compared to normal adult lung

\section{Broncho- \\ Pulmonary \\ Dysplasia}
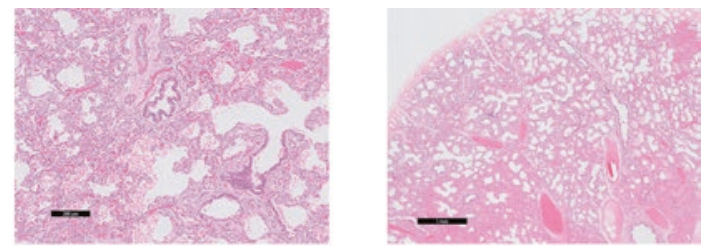

\section{Normal \\ Adult Lung}
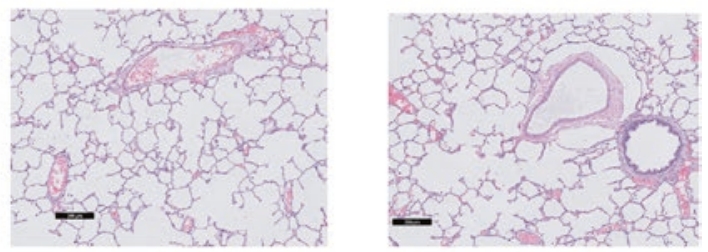

Chronic
Obstructive
Pulmonary
Disease
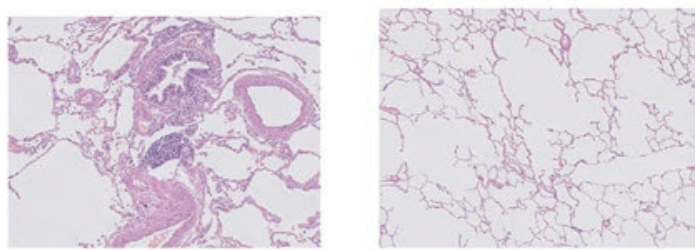

Idiopathic

Pulmonary Fibrosis
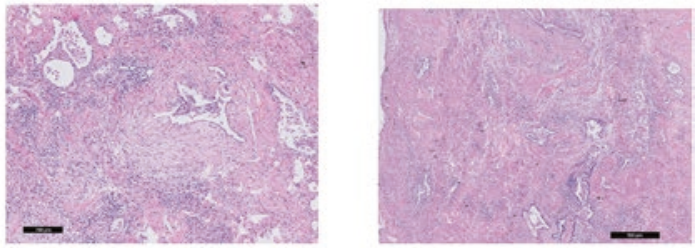

Pulmonary

Arterial Hypertension
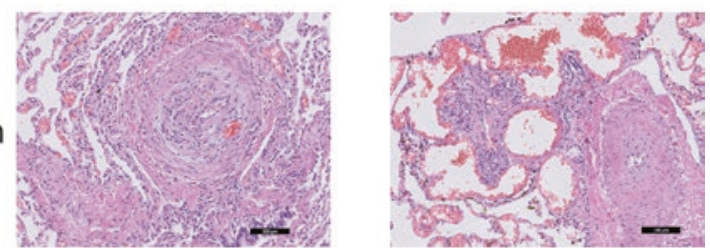

Cystic

Fibrosis
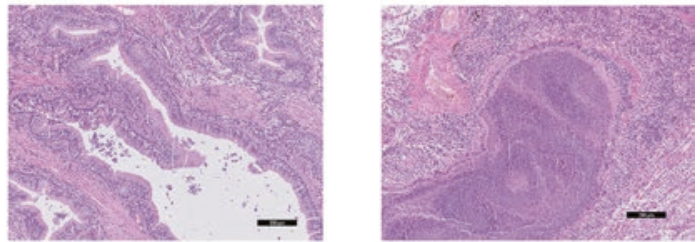

\section{Acute \\ Respiratory \\ Distress \\ Syndrome}

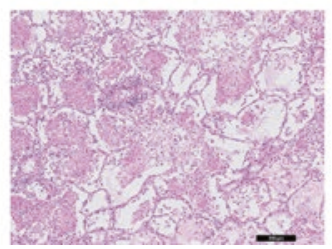

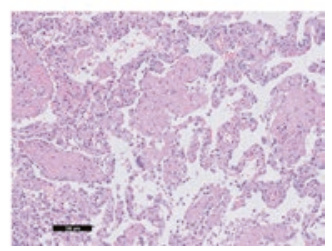


the small airway walls mainly by macrophages and (CD8) T lymphocytes can contribute to the severity of airway limitation [24]. The presence of macrophages and $\mathrm{T}$ lymphocytes, particularly $\mathrm{CD}^{+} \mathrm{T}$ cells, may in addition contribute to changes of the alveolar walls in COPD [25-27]. The chronic presence of these inflammatory cells leads to damage of the alveolar walls, and eventually, because of the lack of tissue repair in COPD [28, 29], could lead to emphysema. Alteration of the pulmonary vasculature is now also considered as a vital component of COPD. This is caused by smooth muscle hypertrophy, which is associated with increased deposition of elastin and collagen [23, 30,31 ] accompanied by apoptosis of the endothelial cells in the arterioles [32], induced by the hypoxic conditions in the COPD lung.

\subsubsection{Treatment of COPD}

There is currently no cure available for COPD, but treatment can control the symptoms, reduce the risk of complications and exacerbations and help slow the progression of the condition. Smoking cessation is the most effective intervention in any treatment plan for COPD, stopping smoking could decrease the risk of death by $18 \%$ [33]. Several kinds of medications are used to treat the symptoms and complications of COPD [34]. Bronchodilators, with long-acting and short-acting forms, can relax the muscles of the airways to help relieve coughing and shortness of breath and make breathing easier [35]. Theophylline can help improve breathing and prevent exacerbations, although with strong side effects [36]. Anti-inflammatory medications, inhaled glucocorticosteroids are commonly combined with long-acting bronchodilators to reduce inflammation in the airways and reduce mucus production [37]. Antibiotics have been successfully used for treatment and prevention of acute exacerbations of COPD [38]. Oxygen therapy and pulmonary rehabilitation programs also provide additional therapies for people with moderate or severe COPD. Surgery is an option for COPD patients with severe emphysema who are not helped sufficiently by medications alone, including lung transplantation.

\subsubsection{Lung Fibrosis}

Pulmonary fibrosis describes a group of interstitial lung diseases (ILDs), mainly characterized by progressive extracellular matrix (ECM) remodelling, increased ECM deposition and irreversible scarring [39]. The quite random accumulation of excess fibrotic ECM leads to mostly irregular stiffening of the lung, with irregular compliance resulting in inadequate ventilation and diffusion with reduced oxygen transfer, breathing difficulties and eventually respiratory failure [40]. It is estimated that ILDs account for approximately $20 \%$ of the spectrum of lung diseases encountered in the practice of pulmonary medicine with varying degrees of pulmonary fibrosis and respiratory dysfunction [39]. Pulmonary fibrosis includes diseases such as scleroderma, radiation and chemotherapy-induced fibrosis and the most common form is idiopathic pulmonary fibrosis (IPF). Although it is challenging to provide evaluations as to how many people are affected by IPF, it is estimated IPF affects approximately three million people worldwide. Approximately 50,000 new cases are diagnosed each year and the death toll due to IPF totals about 40,000 patients in the US each year. How many people are affected by IPF in Europe is not completely known but current estimates suggest that between 37,000 and 40,000 people will be diagnosed each year [41]. More importantly, it is anticipated that the number of individuals diagnosed with IPF will continue to increase, and by 2025 about 132,000 patients are expected to suffer this intractable and debilitating disease. The prognosis for patients with IPF is worse than for most cancers including breast cancer, prostate cancer, some forms of leukaemia and lymphoma [42-45].

IPF is an irreversible and life-threatening lung degenerative disease characterized by the presence of lung scarring, immune infiltrates, and inflammation, which typically leads to respiratory failure. The clinical course of the disease is characterized by a progressive decline in exercise capacity, difficulty breathing, recurrent infections and severe impairment in lung function, which makes the patients dependent on long-term oxygen treatment [46, 47]. 
A myriad of agents such as allergens, chemicals, radiation and environmental particles are risk factors implicated in the pathogenesis of pulmonary fibrotic diseases [40, 46, 48]. The most consistent risk factor for pulmonary fibrotic diseases is cigarette smoking [46, 49]. Injury caused by these triggers leads to wound-healing responses which are generally divided in three phases: injury, inflammation and repair [40]. The presence of a persistent irritant or repeated injury could cause a dysregulation at one or more of these phases.

\subsubsection{Pathology of IPF}

Idiopathic pulmonary fibrosis (IPF) is one of the most well-researched forms of ILDs and is the most commonly diagnosed [46]. IPF is a chronic, progressive fibrotic ILD which is characterized by myo(fibroblast) proliferation, interstitial inflammation and fibrosis within the alveolar wall (see Fig. 1.1), the cause of which is unknown and portrays the histological picture of usual interstitial pneumonia (UIP) [50, 51]. UIP usually presents as severe fibrosis with peripheral alveolar septal thickening and distortion of tissue architecture with a honeycomb structure made up of subpleural cystic airspaces with irregular fibrotic walls and irreversible dilatation of bronchi and bronchioles (bronchiectasis) [49].

Classically IPF was thought to be driven by a chronic inflammatory process; however, although inflammation likely still contributes to the pathogenesis, increasing evidence indicates that an uncontrolled healing response can gradually evolve into a pathologic fibrotic response when important regulatory mechanisms are disrupted and persistent inflammation follows. The persistent inflammation can result in a local milieu of pro-fibrotic cytokines and growth factors such as IL-13 and TGF- $\beta 1$ [52-54]. The pro-fibrotic environment causes fibroblasts to transform into myofibroblasts which are the main producers of ECM which stay active in the presence of TGF- $\beta$, resulting in scarring and destruction of the lung architecture [53]. Increasing research results indicate that the fibrotic response is also driven by abnormally activated alveolar epithelial cells (AECs) [43]. AECs produce mediators that induce the formation of fibroblast and myofibroblast foci through the proliferation of resident mesenchymal cells, attraction of circulating fibrocytes and stimulation of epithelial to mesenchymal transition. The mechanisms that link IPF with ageing and aberrant epithelial activation are unknown; recent research results suggest that the abnormal recapitulation of developmental pathways and epigenetic changes may have a role in driving these changes [44].

\subsubsection{Treatment of IPF}

Two antifibrotic drugs have been approved by the FDA to combat pulmonary fibrosis, namely Nintedanib and Pirfenidone [43, 55]. Nintedanib is a small molecule inhibitor of the receptor tyrosine kinases of the PDGF receptor, FGF receptor and vascular endothelial growth factor receptor, which are believed to play important roles in the pathogenesis of IPF [51, 56]. Pirfenidone has multiple, different, not fully understood, mechanisms of action; however, it appears to have antifibrotic properties via regulation of pro-fibrotic growth factors such as TGF- $\beta$ and tumour necrosis factor- $\alpha$ (TNF- $\alpha)[51,57,58]$. Both drugs slow the progression or reduce the risk of acute exacerbations of IPF but do not stop or reverse pathophysiology, meaning the search for a cure continues and lung transplantation remains the only treatment for IPF that improves quality of life and survival $[55,59,60]$.

\subsubsection{Bronchopulmonary Dysplasia (BPD)}

Annually, globally 15 million babies are born premature (defined as before 37 weeks of gestation) and approximately 2.4 million babies are born before 32 weeks of postmenstrual age [61]. Bronchopulmonary dysplasia (BPD) is the most common chronic lung disease in preterm infants, affecting $\sim 10-50 \%$ of all infants born before 32 weeks, and has long been defined by the need for supplemental oxygen and/or mechanical ventilation 28 days after birth ("old BPD") [62]. However, the advances in obstetric and neonatal care over the last half century have resulted 
in changes in pathophysiology and clinical presentation of BPD, and a new type of BPD has developed [63, 64]. More preterm infants born in the early stages of lung development presently suffer from BPD, with a frequency inversely correlated with gestational age. BPD develops as a result of lung injury caused by maternal pre-eclampsia, chorioamnionitis, postnatal ventilation, hyperoxia and/or inflammation, leading to arrested alveolar and microvascular development (fewer and larger alveoli), airway hyperreactivity and pulmonary hypertension $[62,65]$. This indicates that the pathogenesis of BPD is multifactorial, which means that it is difficult to predict and also prevent short- and long-term consequences of the disease.

\subsubsection{Pathology of BPD}

Whereas the histopathologic lesions in children with "old BPD" are mostly characterized by fibrosis and inflammation, pathology of the "new BPD" is rather characterized by tissue simplification and arrest of alveolarization (fewer and larger alveoli) [63]. An example of lung tissue sections from a 10 weeks old infant with "new" BPD is shown in Fig. 1.1.

\subsubsection{Treatment of BPD}

Over the years, treatment strategies for BPD improved and gentle ventilation strategies and effective non-invasive ventilation devices were implemented to reduce prolonged mechanical ventilation and oxygen exposure. Besides these approaches, other more targeted therapies including low-dose hydrocortisone, non-invasive surfactant instillation, retinoic acid and antiinflammatory strategies have been trialled, all which have been limited by serious side effects [64]. In addition, with increased survival of infants, interest in stem cell-related therapies has emerged as mesenchymal stem cells (MSCs) play a key role in alveolarization and lung tissue repair [13]. Clinical trials of MSCs in chronic lung diseases have demonstrated short-term safety and tolerability; however, studies have also shown populations of MSCs with adverse pro-inflammatory and myofibroblastic characteristics [66].
In hyperoxic rodent models of BPD, as shown by a systemic review of the literature, MSC treatment resulted in a significant improvement in lung injury, with the primary outcome of lung alveolarization and secondary outcomes, including inflammation, pulmonary hypertension, lung fibrosis, apoptosis and lung angiogenesis [67]. Likewise, MSC-derived conditioned media conferred therapeutic benefit for alveolarization, pulmonary artery remodelling, and angiogenesis. Cell-based therapies may represent the next breakthrough therapy for the treatment of BPD; however, there remain barriers to implementation as well as gaps in knowledge of the role of endogenous MSCs in the pathogenesis of BPD.

\subsubsection{Pulmonary Arterial Hypertension (PAH)}

Pulmonary hypertension describes conditions in which high blood pressure affects the arteries in the lungs and the right side of the heart. It is a chronic, progressive condition that can lead to right heart failure which can be lethal if not treated appropriately. As the presentation of this disease is similar to many other lung diseases (shortness of breath (dyspnea) —initially while exercising then building up while at rest, fatigue, dizziness or fainting (syncope), chest pressure or pain), this can lead to a delay in accurate timely diagnoses. Pulmonary hypertension is classified into five groups, based on World Health Organisation (WHO) classifications (groups) defined by the pathophysiology of the disease [68-70]. The most common form is WHO group 1 , which refers to patients who have pulmonary arterial hypertension (PAH).

$\mathrm{PAH}$ is a rare disease, affecting about 15 people per million worldwide. The cause of PAH is generally unknown, it is often referred to as idiopathic PAH, although genetic predisposition is recognised in familiar PAH. There are a number of pre-disposing conditions, including systemic sclerosis (particularly in the presence of ILD), human immunodeficiency virus and methamphetamine exposure, that are recognised to increase the prevalence of PAH [71-73]. 


\subsubsection{Pathology of PAH}

In PAH in early/mild lesions the small arteries in the lungs $(<500 \mu \mathrm{m}$ diameter) become obstructed, which leads to an increase in blood pressure due to the increased resistance. The obstruction is driven by remodelling of the artery walls including hypertrophy in the medial layer, proliferation and fibrotic (ECM deposition) changes in the intima and thickening of the advential layer accompanied by inflammatory infiltrates $[69,74]$. In more severe disease, the so-called complex or plexiform lesions develop with a glomeruloid vascular process and a dilated venous part added to the obstructed arteriole [69] (see Fig. 1.1). Vasoconstriction, associated with overproduction of endothelin-1 (vasoconstrictor) or underproduction of nitric oxide or prostacyclin (or both) (vasodilators), is often a disease characteristic. Mutations in the bone morphogenic protein receptor type II gene are the most common cause of familiar PAH [75] and are also thought to play a role in sporadic cases though it is less clear exactly how.

\subsubsection{Treatment of PAH}

Patients with untreated PAH have a median life expectancy of 2.8 years [76]. However, recent advances in therapeutic approaches for the management of PAH have advanced the survival times significantly $[68,77,78]$. Over the last two decades, advances in understanding and pursuit of the pathophysiology of PAH have enabled the development of pharmaceutical agents that target three critical pathways; prostacyclin analogues replace the deficiency of endogenous prostacyclins, endothelin receptor antagonists counteract the overproduction of endothelin and phosphodiesterase-5 inhibitors act to account for the reduced activity of the nitric oxide pathway $[79,80]$. Worldwide accepted treatment algorithms have significantly improved the survival outcomes for many PAH patients [68]; however, it remains a fatal disease.

\subsubsection{Cystic Fibrosis (CF)}

Cystic fibrosis (CF) is a progressive lifethreatening genetic disease involving multiple- organs, including the lungs, pancreas, sweat glands, biliary tract, salivary glands and the vas deferens. The lung pathology is the major cause of disease morbidity and generally is the cause of death in these patients. CF is an autosomal recessive disease affecting approximately 75,000 worldwide. It is most common in Caucasians of northern European descent, and least common in Asian-Americans [81]. The life expectancy of an individual with $\mathrm{CF}$ has increased steadily since the recognition of the disease in the 1950s; with advances in symptomatic treatments the estimated life expectancy for individuals with $\mathrm{CF}$, born in 2016, is greater than 45 years (Cystic fibrosis registry 2016).

\subsubsection{Pathology of CF}

$\mathrm{CF}$ is the most common lethal autosomal recessive disease in Caucasians, resulting from mutations in the gene encoding the cystic fibrosis transmembrane conductance regulator (CFTR). More than 1700 mutations have been recognised in the CFTR gene that lead to CF [82]. These mutations are divided into six classes depending on how the change affects the protein synthesis, trafficking, function or stability of the CFTR [83]. The CFTR, expressed apically in epithelial cell membranes, is a transmembrane channel that is important for regulating cellular salt and fluid homeostasis. It is a chloride $\left(\mathrm{Cl}^{-}\right)$and bicarbonate $\left(\mathrm{HCO}_{3}{ }^{-}\right)$ion channel. Mutations in this channel result in disrupted flow of $\mathrm{Cl}^{-}$and $\mathrm{HCO}_{3}{ }^{-}$through epithelial cells of multiple organs, resulting in aberrant functioning of those organs.

In the lung, disruption of the CFTR impacts the hydration of mucus at the epithelial cell surface (the lack of $\mathrm{Cl}^{-}$transport) [84] and allows tethering of mucus, rather than clearance as a result of the lack of the key alkalisation effector $\left(\mathrm{HCO}_{3}{ }^{-}\right)[85,86]$. These mutations result in the accumulation of a thick, sticky mucus in the airways driving chronic inflammation and enabling recurrent respiratory infections usually initiating soon after birth. Animal studies reflect the pathological changes in the airways, also suggesting the trachea is narrowed. The neutrophil influx, in response to the ongoing airway inflammation, leads to further inflammation as a result of 
the release of neutrophil elastase and other proinflammatory cytokines [87, 88]. This vicious cycle drives remodelling of the airway wall tissues, resulting in air trapping and bronchiectasis (see Fig. 1.1).

\subsubsection{Treatment of CF}

The main treatment approaches for $\mathrm{CF}$ aim to modulate symptoms but are not able to cure the disease [89]. Preventing and reducing the severity of respiratory infections is a major focus, usually with antibiotics. Airway inflammation is addressed with steroids and non-steroidal anti-inflammatory drugs, while $\beta$ agonists are used in combination with hypertonic saline to reduce the viscosity of the mucus and relax the airways. More recently there have been exciting developments of therapeutics aimed at "correcting" and "potentiating" CFTR. Vertex Pharmaceuticals have obtained FDA approval for the use of VX-770 (CFTR corrector, ivacaftor, trade name Kalydeco) [90, 91] and VX-809 (CFTR potentiator, lumacaftor) [92] for clinical use in $\mathrm{CF}$ patients with specific mutations [93]. Combination therapies that aim to improve the functionality and stability of the CFTR at the epithelia cell surface are now being developed [94]. These approaches have made significant advances and improvements in the quality of life for many patients with $\mathrm{CF}$, but they are not effective for all mutations of CFTR. These approaches help to reduce the ongoing inflammation, but it is not clear if they are able to address the structural remodelling in the lung tissues.

\subsubsection{Acute Respiratory Distress Syndrome (ARDS)}

Acute respiratory distress syndrome (ARDS) is a relatively common life-threatening syndrome that affects 200,000 adults annually in the US and is the cause of almost 75,000 deaths each year. Worldwide more the three million people are affected, accounting for $10 \%$ of admissions to intensive care units annually. It is a major clinical problem that is the end result of a number of aetiologies of lung injury. ARDS is an acute cause of rapidly progressing respiratory failure which is often associated with multiple organ failure. Many events have been suggested as risk factors for the development of ARDS. Respiratory infections are the most common causes, particularly bacterial pneumonia, although there is increasing recognition of the impact of respiratory viruses, pathogenic fungi and parasites (especially in immunocompromised patients). There is an emerging awareness of genetic susceptibilities in ARDS patients [95].

\subsubsection{Pathology of ARDS}

The pathophysiology of ARDS is recognised to occur in three overlapping phases [96, 97] with a characteristic and pathognomonic histopathology termed diffuse alveolar damage (DAD). The initial injury to the lung causes a disruption of the alveolar endothelium and epithelial cell barrier accompanied by oedema in the airspaces [98]. In the case of an infectious origin, neutrophils and macrophages are the major cell types that infiltrate the airspaces, but with many aetiologies inflammation is inconspicuous. In a somewhat later phase, there is also leakage of thrombin and protein amongst others leading to hyaline membranes. There are also vascular changes leading to the formation of microthrombi and changes in vasomotor tone. The last phase is a repair phase in which the alveolar epithelium is regenerated through proliferation of the type II cells and differentiation to type I cells. This enables restoration of the permeability of the basal membranes and allows fluid clearance from the airspaces. The vascular changes also reverse during this stage. The final stage can be complete resolution but very often is characterized by impressive thickening of alveolar septa by fibroblast proliferation without obvious collagen fibrosis with subsequent severe lung function problems and often a poor prognosis. In some cases a fibrotic phase can follow where collagen and other ECM proteins are deposited resulting in a partially stable fibrotic lung. The factors regulating the fibrotic/fibroblastic phase in DAD/ARDS are not known but mechanical ventilation, in particular 
with high pressure and high oxygen concentration is thought to be an important pathogenetic component [99].

\subsubsection{Treatment of ARDS}

Current therapeutic management of ARDS consists of the use of supportive therapeutic approaches that are beneficial for all critical care patients as there are no effective ARDS-specific therapies to date. Lung-protective mechanical ventilation is the major intervention for ARDS patients. For a subset of patients there is evidence that fluid management is also beneficial [52]. While the mortality of ARDS has been declining modestly in recent years [100], likely due to improvements in supportive therapies, the overall mortality rates remain unacceptably high and the long-term impact for survivors is also considerable [101].

\subsection{Conclusion}

It is clear that there is an urgent need, for many chronic lung diseases, to develop better therapeutic approaches. Given the lack of curative treatments and the often-progressive pathology of the lung diseases described in this chapter, particular interest exists in mechanisms aimed at helping with the repair of the lung structure and function. There is emerging excitement about the potential for stem/progenitor cell-based therapeutic approaches, but there is much still to be done to understand the full potential of these approaches for lung patients [102].

Preclinical studies suggest that cell therapy using mesenchymal stromal cells represents a potential new treatment strategy for lung diseases [102-104]. In these models, MSCs displayed the potential to regenerate and restore the architecture of lung tissue, reflected by their ability to repair airway epithelial and endothelial cells. Although it is not clear what the exact mechanism behind this is, it possibly involves the secretion of various growth factors and cytokines. However, as yet, no cell-based therapy has been shown to be both safe and effective for any lung disease in patients so the field waits to see the developments in the next few years.

\section{References}

1. WHO methods and data sources for global causes of death, 2000-2016. Department of Information EaR, WHO G World Health Organization Publisher. 2018. https://www.who.int/gho/mortality_burden_disease/ causes_death/top_10/en/.

2. Disease burden and mortality estimates, CauseSpecific Mortality, 2000-2016. World Health Organization Publisher. 2018. https://www.who.int/ healthinfo/global_burden_disease/estimates/en/.

3. Ahluwalia N, Shea BS, Tager AM. New therapeutic targets in idiopathic pulmonary fibrosis aiming to Rein in runaway wound-healing responses. Am J Respir Crit Care Med. 2014;190(8):867-78.

4. Faner R, Rojas M, MacNee W, Agusti A. Abnormal lung aging in chronic obstructive pulmonary disease and idiopathic pulmonary fibrosis. Am J Respir Crit Care Med. 2012;186(4):306-13.

5. Hogan BL, Barkauskas CE, Chapman HA, Epstein JA, Jain R, Hsia CC, et al. Repair and regeneration of the respiratory system: complexity, plasticity, and mechanisms of lung stem cell function. Cell Stem Cell. 2014;15(2):123-38.

6. McGowan SE. Extracellular matrix and the regulation of lung development and repair. FASEB J. 1992;6(11):2895-904.

7. Rock JR, Hogan BL. Epithelial progenitor cells in lung development, maintenance, repair, and disease. Annu Rev Cell Dev Biol. 2011;27:493-512.

8. Wansleeben C, Barkauskas CE, Rock JR, Hogan BL. Stem cells of the adult lung: their development and role in homeostasis, regeneration, and disease. Wiley Interdiscip Rev Dev Biol. 2013;2(1):131-48.

9. Warburton D, Gauldie J, Bellusci S, Shi W. Lung development and susceptibility to chronic obstructive pulmonary disease. Proc Am Thorac Soc. 2006;3(8):668-72.

10. Brandsma CA, de Vries M, Costa R, Woldhuis RR, Konigshoff M, Timens W. Lung ageing and COPD: is there a role for ageing in abnormal tissue repair? Eur Respir Rev. 2017;26(146):170073.

11. Everaerts S, Lammertyn EJ, Martens DS, De Sadeleer LJ, Maes K, van Batenburg AA, et al. The aging lung: tissue telomere shortening in health and disease. Respir Res. 2018;19(1):95.

12. Zacharias WJ, Frank DB, Zepp JA, Morley MP, Alkhaleel FA, Kong J, et al. Regeneration of the lung alveolus by an evolutionarily conserved epithelial progenitor. Nature. 2018;555(7695):251-5.

13. Mobius MA, Thebaud B. Bronchopulmonary dysplasia: where have all the stem cells gone?: origin and (potential) function of resident lung stem cells. Chest. 2017;152(5):1043-52.

14. Barkauskas CE, Cronce MJ, Rackley CR, Bowie EJ, Keene DR, Stripp BR, et al. Type 2 alveolar cells are stem cells in adult lung. J Clin Invest. 2013;123(7):3025-36. 
15. Tata PR, Rajagopal J. Plasticity in the lung: making and breaking cell identity. Development. 2017;144(5):755-66.

16. Hogg JC, Timens W. The pathology of chronic obstructive pulmonary disease. Annu Rev Pathol. 2009;4:435-59.

17. Singh D, Agusti A, Anzueto A, Barnes PJ, Bourbeau J, Celli BR, et al. Global strategy for the diagnosis, management, and prevention of chronic obstructive lung disease: the GOLD science committee report 2019. Eur Respir J. 2019;53(5):pii: 1900164.

18. Gooptu B, Ekeowa UI, Lomas DA. Mechanisms of emphysema in alpha1-antitrypsin deficiency: molecular and cellular insights. Eur Respir J. 2009;34(2):475-88.

19. Forey BA, Thornton AJ, Lee PN. Systematic review with meta-analysis of the epidemiological evidence relating smoking to COPD, chronic bronchitis and emphysema. BMC Pulm Med. 2011;11:36.

20. Berg K, Wright JL. The pathology of chronic obstructive pulmonary disease: progress in the 20th and 21st centuries. Arch Pathol Lab Med. 2016;140(12):1423-8.

21. Shapiro SD, Ingenito EP. The pathogenesis of chronic obstructive pulmonary disease: advances in the past 100 years. Am J Respir Cell Mol Biol. 2005;32(5):367-72.

22. Taraseviciene-Stewart L, Voelkel NF. Molecular pathogenesis of emphysema. $\mathrm{J}$ Clin Invest. 2008;118(2):394-402.

23. Pini L, Pinelli V, Modina D, Bezzi M, Tiberio L, Tantucci C. Central airways remodeling in COPD patients. Int J Chron Obstruct Pulmon Dis. 2014;9:927-32.

24. Baraldo S, Turato G, Saetta M. Pathophysiology of the small airways in chronic obstructive pulmonary disease. Respiration. 2012;84(2):89-97.

25. Saetta M, Di Stefano A, Turato G, Facchini FM, Corbino L, Mapp CE, et al. CD8+ T-lymphocytes in peripheral airways of smokers with chronic obstructive pulmonary disease. Am J Respir Crit Care Med. 1998;157(3 Pt 1):822-6.

26. Hogg JC, Chu F, Utokaparch S, Woods R, Elliott WM, Buzatu L, et al. The nature of small-airway obstruction in chronic obstructive pulmonary disease. N Engl J Med. 2004;350(26):2645-53.

27. Barnes PJ. Inflammatory mechanisms in patients with chronic obstructive pulmonary disease. J Allergy Clin Immunol. 2016;138(1):16-27.

28. Hogg JC, McDonough JE, Gosselink JV, Hayashi $\mathrm{S}$. What drives the peripheral lung-remodeling process in chronic obstructive pulmonary disease? Proc Am Thorac Soc. 2009;6(8):668-72.

29. Brandsma CA, van den Berge M, Postma DS, Jonker MR, Brouwer S, Pare PD, et al. A large lung gene expression study identifying fibulin-5 as a novel player in tissue repair in COPD. Thorax. 2015;70(1):21-32.

30. Wright JL, Levy RD, Churg A. Pulmonary hypertension in chronic obstructive pulmonary disease: cur- rent theories of pathogenesis and their implications for treatment. Thorax. 2005;60(7):605-9.

31. Peinado VI, Pizarro S, Barbera JA. Pulmonary vascular involvement in COPD. Chest. 2008;134(4):808-14.

32. Nana-Sinkam SP, Lee JD, Sotto-Santiago S, Stearman RS, Keith RL, Choudhury Q, et al. Prostacyclin prevents pulmonary endothelial cell apoptosis induced by cigarette smoke. Am J Respir Crit Care Med. 2007;175(7):676-85.

33. Decramer M, Janssens W, Miravitlles M. Chronic obstructive pulmonary disease. Lancet. 2012;379(9823):1341-51.

34. Global initiative for Chronic Lung Disease; Pocket Guide to COPD diagnosis, management and prevention. GOLD committee Publisher. 2017. https:// goldcopd.org/wp-content/uploads/2016/12/wmsGOLD-2017-Pocket-Guide.pdf.

35. Cazzola M, Page CP, Calzetta L, Matera MG. Pharmacology and therapeutics of bronchodilators. Pharmacol Rev. 2012;64(3):450-504.

36. Barr RG, Rowe BH, Camargo CA. Methylxanthines for exacerbations of chronic obstructive pulmonary disease. Cochrane Database Syst Rev. 2003;2:CD002168.

37. Gartlehner G, Hansen RA, Carson SS, Lohr KN. Efficacy and safety of inhaled corticosteroids in patients with COPD: a systematic review and meta-analysis of health outcomes. Ann Fam Med. 2006;4(3):253-62.

38. Wilson R, Sethi S, Anzueto A, Miravitlles M. Antibiotics for treatment and prevention of exacerbations of chronic obstructive pulmonary disease. J Infect. 2013;67(6):497-515.

39. Meyer KC. Pulmonary fibrosis, part I: epidemiology, pathogenesis, and diagnosis. Expert Rev Respir Med. 2017;11(5):343-59.

40. Wilson MS, Wynn TA. Pulmonary fibrosis: pathogenesis, etiology and regulation. Mucosal Immunol. 2009;2(2):103-21.

41. Pulmonary fibrosis patient information guide. Pulmonary Fibrosis Foundation Publisher. 2015. https://www.pulmonaryfibrosis.org/docs/defaultsource/patient-information-guides/pff_patinfoguide_v0215.pdf.

42. Nalysnyk L, Cid-Ruzafa J, Rotella P, Esser D. Incidence and prevalence of idiopathic pulmonary fibrosis: review of the literature. Eur Respir Rev. 2012;21(126):355-61.

43. King TE Jr, Pardo A, Selman M. Idiopathic pulmonary fibrosis. Lancet. 2011;378(9807):1949-61.

44. Kropski JA, Lawson WE, Young LR, Blackwell TS. Genetic studies provide clues on the pathogenesis of idiopathic pulmonary fibrosis. Dis Model Mech. 2013;6(1):9-17.

45. Navaratnam V, Fleming KM, West J, Smith CJ, Jenkins RG, Fogarty A, et al. The rising incidence of idiopathic pulmonary fibrosis in the U.K. Thorax. 2011;66(6):462-7.

46. Lederer DJ, Martinez FJ. Idiopathic pulmonary fibrosis. N Engl J Med. 2018;378(19):1811-23. 
47. Chilosi M, Poletti V, Rossi A. The pathogenesis of COPD and IPF: distinct horns of the same devil? Respir Res. 2012;13:3.

48. Sack C, Raghu G. Idiopathic pulmonary fibrosis: unmasking cryptogenic environmental factors. Eur Respir J. 2019;53(2):1801699.

49. Martinez FJ, Collard HR, Pardo A, Raghu G, Richeldi L, Selman M, et al. Idiopathic pulmonary fibrosis. Nat Rev Dis Primers. 2017;3:17074.

50. Travis WD, Costabel U, Hansell DM, King TE Jr, Lynch DA, Nicholson AG, et al. An official American Thoracic Society/European Respiratory Society statement: update of the international multidisciplinary classification of the idiopathic interstitial pneumonias. Am J Respir Crit Care Med. 2013;188(6):733-48.

51. Aryal S, Nathan SD. An update on emerging drugs for the treatment of idiopathic pulmonary fibrosis. Expert Opin Emerg Drugs. 2018;23(2):159-72.

52. Famous KR, Delucchi K, Ware LB, Kangelaris KN, Liu KD, Thompson BT, et al. Acute respiratory distress syndrome subphenotypes respond differently to randomized fluid management strategy. Am J Respir Crit Care Med. 2017;195(3):331-8.

53. Meng XM, Nikolic-Paterson DJ, Lan HY. TGF-beta: the master regulator of fibrosis. Nat Rev Nephrol. 2016;12(6):325-38.

54. Fichtner-Feigl S, Strober W, Kawakami K, Puri RK, Kitani A. IL-13 signaling through the IL-13alpha2 receptor is involved in induction of TGF-beta1 production and fibrosis. Nat Med. 2006;12(1):99-106.

55. Richeldi L, du Bois RM, Raghu G, Azuma A, Brown KK, Costabel U, et al. Efficacy and safety of nintedanib in idiopathic pulmonary fibrosis. N Engl J Med. 2014;370(22):2071-82.

56. Wollin L, Wex E, Pautsch A, Schnapp G, Hostettler KE, Stowasser S, et al. Mode of action of nintedanib in the treatment of idiopathic pulmonary fibrosis. Eur Respir J. 2015;45(5):1434-45.

57. Conte E, Gili E, Fagone E, Fruciano M, Iemmolo $\mathrm{M}$, Vancheri C. Effect of pirfenidone on proliferation, TGF-beta-induced myofibroblast differentiation and fibrogenic activity of primary human lung fibroblasts. Eur J Pharm Sci. 2014;58:13-9.

58. Taniguchi H, Ebina M, Kondoh Y, Ogura T, Azuma A, Suga M, et al. Pirfenidone in idiopathic pulmonary fibrosis. Eur Respir J. 2010;35(4):821-9.

59. Karimi-Shah BA, Chowdhury BA. Forced vital capacity in idiopathic pulmonary fibrosis--FDA review of pirfenidone and nintedanib. N Engl J Med. 2015;372(13):1189-91.

60. Noble PW, Albera C, Bradford WZ, Costabel U, du Bois RM, Fagan EA, et al. Pirfenidone for idiopathic pulmonary fibrosis: analysis of pooled data from three multinational phase 3 trials. Eur Respir J. 2016;47(1):243-53.

61. Blencowe H, Cousens S, Oestergaard MZ, Chou D, Moller AB, Narwal R, et al. National, regional, and worldwide estimates of preterm birth rates in the year 2010 with time trends since 1990 for selected countries: a systematic analysis and implications. Lancet. 2012;379(9832):2162-72.

62. Jobe AH. Mechanisms of lung injury and bronchopulmonary dysplasia. Am J Perinatol. 2016;33(11):1076-8.

63. Coalson JJ. Pathology of new bronchopulmonary dysplasia. Semin Neonatol. 2003;8(1):73-81.

64. Principi N, Di Pietro GM, Esposito S. Bronchopulmonary dysplasia: clinical aspects and preventive and therapeutic strategies. J Transl Med. 2018;16(1):36.

65. Collins JJP, Tibboel D, de Kleer IM, Reiss IKM, Rottier RJ. The future of bronchopulmonary dysplasia: emerging pathophysiological concepts and potential new avenues of treatment. Front Med (Lausanne). 2017;4:61.

66. Simones AA, Beisang DJ, Panoskaltsis-Mortari A, Roberts KD. Mesenchymal stem cells in the pathogenesis and treatment of bronchopulmonary dysplasia: a clinical review. Pediatr Res. 2018;83(1-2):308-17.

67. Augustine S, Avey MT, Harrison B, Locke T, Ghannad M, Moher D, et al. Mesenchymal stromal cell therapy in bronchopulmonary dysplasia: systematic review and meta-analysis of preclinical studies. Stem Cells Transl Med. 2017;6(12):2079-93.

68. Kim D, George MP. Pulmonary hypertension. Med Clin North Am. 2019;103(3):413-23.

69. Humbert M, Guignabert C, Bonnet S, Dorfmuller P, Klinger JR, Nicolls MR, et al. Pathology and pathobiology of pulmonary hypertension: state of the art and research perspectives. Eur Respir J. 2019;53(1):1801887.

70. Simonneau G, Montani D, Celermajer DS, Denton CP, Gatzoulis MA, Krowka M, et al. Haemodynamic definitions and updated clinical classification of pulmonary hypertension. Eur Respir J. 2019;53(1):1801913.

71. Badesch DB, Champion HC, Sanchez MA, Hoeper MM, Loyd JE, Manes A, et al. Diagnosis and assessment of pulmonary arterial hypertension. J Am Coll Cardiol. 2009;54(1 Suppl):S55-66.

72. Launay D, Mouthon L, Hachulla E, Pagnoux C, de Groote P, Remy-Jardin M, et al. Prevalence and characteristics of moderate to severe pulmonary hypertension in systemic sclerosis with and without interstitial lung disease. J Rheumatol. 2007;34(5):1005-11.

73. Avouac J, Airo P, Meune C, Beretta L, Dieude P, Caramaschi $\mathrm{P}$, et al. Prevalence of pulmonary hypertension in systemic sclerosis in European Caucasians and metaanalysis of 5 studies. J Rheumatol. 2010;37(11):2290-8.

74. Tuder RM, Abman SH, Braun T, Capron F, Stevens T, Thistlethwaite PA, et al. Development and pathology of pulmonary hypertension. J Am Coll Cardiol. 2009;54(1 Suppl):S3-9.

75. Soubrier F, Chung WK, Machado R, Grunig E, Aldred M, Geraci M, et al. Genetics and genomics of pulmonary arterial hypertension. J Am Coll Cardiol. 2013;62(25 Suppl):D13-21. 
76. D'Alonzo GE, Barst RJ, Ayres SM, Bergofsky EH, Brundage BH, Detre KM, et al. Survival in patients with primary pulmonary hypertension. Results from a national prospective registry. Ann Intern Med. 1991;115(5):343-9.

77. Humbert M, Sitbon O, Chaouat A, Bertocchi M, Habib G, Gressin V, et al. Survival in patients with idiopathic, familial, and anorexigen-associated pulmonary arterial hypertension in the modern management era. Circulation. 2010;122(2):156-63.

78. Krowka MJ, Miller DP, Barst RJ, Taichman D, Dweik RA, Badesch DB, et al. Portopulmonary hypertension: a report from the US-based REVEAL registry. Chest. 2012;141(4):906-15.

79. Matsubara H, Ogawa A. Treatment of idiopathic/ hereditary pulmonary arterial hypertension. J Cardiol. 2014;64(4):243-9.

80. Kondo T, Okumura N, Adachi S, Murohara T. Editors' choice pulmonary hypertension: diagnosis, management, and treatment. Nagoya J Med Sci. 2019;81(1):19-30.

81. Hamosh A, FitzSimmons SC, Macek M Jr, Knowles MR, Rosenstein BJ, Cutting GR. Comparison of the clinical manifestations of cystic fibrosis in black and white patients. J Pediatr. 1998;132(2):255-9.

82. Pranke I, Golec A, Hinzpeter A, Edelman A, SermetGaudelus I. Emerging therapeutic approaches for cystic fibrosis. From gene editing to personalized medicine. Front Pharmacol. 2019;10:121.

83. O'Sullivan BP, Freedman SD. Cystic fibrosis. Lancet. 2009;373(9678):1891-904.

84. Boucher RC. Evidence for airway surface dehydration as the initiating event in CF airway disease. J Intern Med. 2007;261(1):5-16.

85. Shah VS, Meyerholz DK, Tang XX, Reznikov L, Abou Alaiwa M, Ernst SE, et al. Airway acidification initiates host defense abnormalities in cystic fibrosis mice. Science. 2016;351(6272):503-7.

86. Tang XX, Ostedgaard LS, Hoegger MJ, Moninger TO, Karp PH, McMenimen JD, et al. Acidic pH increases airway surface liquid viscosity in cystic fibrosis. J Clin Invest. 2016;126(3):879-91.

87. Nichols DP, Chmiel JF. Inflammation and its genesis in cystic fibrosis. Pediatr Pulmonol. 2015;50(Suppl 40):S39-56.

88. Griese M, Kappler M, Gaggar A, Hartl D. Inhibition of airway proteases in cystic fibrosis lung disease. Eur Respir J. 2008;32(3):783-95.

89. Rafeeq MM, Murad HAS. Cystic fibrosis: current therapeutic targets and future approaches. J Transl Med. 2017;15(1):84.

90. Van Goor F, Straley KS, Cao D, Gonzalez J, Hadida S, Hazlewood A, et al. Rescue of DeltaF508-CFTR trafficking and gating in human cystic fibrosis airway primary cultures by small molecules. Am J Physiol Lung Cell Mol Physiol. 2006;290(6):L1117-30.
91. Van Goor F, Hadida S, Grootenhuis PD, Burton B, Stack JH, Straley KS, et al. Correction of the F508del-CFTR protein processing defect in vitro by the investigational drug VX-809. Proc Natl Acad Sci U S A. 2011;108(46):18843-8.

92. Van Goor F, Hadida S, Grootenhuis PD, Burton B, Cao D, Neuberger T, et al. Rescue of CF airway epithelial cell function in vitro by a CFTR potentiator, VX-770. Proc Natl Acad Sci U S A. 2009;106(44):18825-30.

93. Cabrini G. Innovative therapies for cystic fibrosis: the road from treatment to cure. Mol Diagn Ther. 2019;23(2):263-79.

94. Chaudary N. Triplet CFTR modulators: future prospects for treatment of cystic fibrosis. Ther Clin Risk Manag. 2018;14:2375-83.

95. Tejera P, Meyer NJ, Chen F, Feng R, Zhao Y, O'Mahony DS, et al. Distinct and replicable genetic risk factors for acute respiratory distress syndrome of pulmonary or extrapulmonary origin. J Med Genet. 2012;49(11):671-80.

96. Shaw TD, McAuley DF, O'Kane CM. Emerging drugs for treating the acute respiratory distress syndrome. Expert Opin Emerg Drugs. 2019;24(1):29-41.

97. Matthay MA, Ware LB, Zimmerman GA. The acute respiratory distress syndrome. J Clin Invest. 2012;122(8):2731-40.

98. Sharp C, Millar AB, Medford AR. Advances in understanding of the pathogenesis of acute respiratory distress syndrome. Respiration. 2015;89(5): 420-34.

99. Cabrera-Benitez NE, Laffey JG, Parotto M, Spieth PM, Villar J, Zhang H, et al. Mechanical ventilationassociated lung fibrosis in acute respiratory distress syndrome: a significant contributor to poor outcome. Anesthesiology. 2014;121(1):189-98.

100. Maca J, Jor O, Holub M, Sklienka P, Bursa F, Burda $\mathrm{M}$, et al. Past and present ARDS mortality rates: a systematic review. Respir Care. 2017;62(1):113-22.

101. Kapfhammer HP, Rothenhausler HB, Krauseneck T, Stoll C, Schelling G. Posttraumatic stress disorder and health-related quality of life in long-term survivors of acute respiratory distress syndrome. Am J Psychiatry. 2004;161(1):45-52.

102. Kruk D, Heijink IH, Slebos DJ, Timens W, Ten Hacken NH. Mesenchymal stromal cells to regenerate emphysema: on the horizon? Respiration. 2018;96(2):148-58.

103. Broekman W, Khedoe P, Schepers K, Roelofs H, Stolk J, Hiemstra PS. Mesenchymal stromal cells: a novel therapy for the treatment of chronic obstructive pulmonary disease? Thorax. 2018;73(6):565-74.

104. Ikonomou L, Wagner DE, Turner L, Weiss DJ. Translating basic research into safe and effective cell-based treatments for respiratory diseases. Ann Am Thorac Soc. 2019;16(6):657-68. 